\title{
Emerging role of microRNA-21 in cancer (Review)
}

\author{
YIN-HSUN FENG ${ }^{1,2}$ and CHAO-JUNG TSAO ${ }^{3}$ \\ ${ }^{1}$ Division of Hematology and Oncology, Department of Internal Medicine, Chi-Mei Medical Center, Tainan 71004; \\ ${ }^{2}$ Department of Nursing, College of Medicine and Life Science, Chung Hwa University of \\ Medical Technology, Tainan 71703; ${ }^{3}$ Department of Hematology and Oncology, \\ Chi-Mei Medical Center, Tainan 73657, Taiwan, R.O.C.
}

Received April 19, 2016; Accepted August 18, 2016

DOI: $10.3892 /$ br.2016.747

\begin{abstract}
MicroRNAs (miRs) are a class of single-stranded RNA molecules of 15-27 nucleotides in length that regulate gene expression at the post-translational level. miR-21 is one of the earliest identified cancer-promoting 'oncomiRs', targeting numerous tumor suppressor genes associated with proliferation, apoptosis and invasion. The regulation of miR-21 and its role in carcinogenesis have been extensively investigated. Recent studies have focused on the diagnostic and prognostic value of miR-21 as well as its implication in the drug resistance of human malignancies. The further use of miR-21 as a biomarker and target for cancer treatments is likely to improve the outcome for patients with cancer. The present review highlights recent findings associated with the importance of miR-21 in hematological and non-hematological malignancies.
\end{abstract}

Correspondence to: Dr Yin-Hsun Feng, Division of Hematology and Oncology, Department of Internal Medicine, Chi-Mei Medical Center, 901 Chung-Hwa Road, Tainan 71004, Taiwan, R.O.C.

E-mail: yinhsun.feng@gmail.com

Professor Chao-Jung Tsao, Department of Hematology and Oncology, Chi-Mei Medical Center, Liouying, 201 Taikang Village, Tainan 73657, Taiwan, R.O.C.

E-mail: cjt@mail.chimei.org.tw

Abbreviations: miRNA, microRNA; IL, interleukin; AP-1, activated protein-1; NFI, nuclear factor I; PDCD4, programmed cell death protein 4; BTG2, B-cell translocation gene 2; RECK, reversion-induced cystine-rich protein with Kazal motifs; TIMP3, tissue inhibitor of metalloproteinases 3; HPV, human papilloma virus; PTEN, phosphatase and tensin homologue deleted on chromosome 10; DLBCL, diffuse large B-cell lymphoma; EBV, Epstein-Barr virus; CLL, chronic lymphocytic leukemia; T-ALL, T-cell acute lymphoblastic leukemia; HER2, human epidermal growth factor receptor 2; STAT3, signal transducer and activator of transcription 3; NSCLC, non-small cell lung cancer; EGFR, epidermal growth factor receptor; TKI, tyrosine kinase inhibitor

Key words: microRNA-21, carcinogenesis, hematological malignancy

\section{Contents}

\author{
1. Introduction \\ 2. Biological function of miR-21 \\ 3. Regulation of miR-21 \\ 4. Carcinogenesis \\ 5. miR-21 and hematological malignancies \\ 6. miR-21 and solid tumors \\ 7. Conclusion
}

\section{Introduction}

MicroRNAs (miRs) are a class of naturally occurring short non-coding RNA molecules of 15-27 nucleotides in length that regulate eukaryotic gene expression at the post-transcriptional level. Almost 2,000 human miRNAs have been identified through cloning and/or sequence analysis (1). They have key regulatory roles in the development, differentiation and apoptosis of normal cells, as well as in the determination of the final phenotype of cancer cells, affecting carcinogenesis and metastatic potential (2). miR-21 is an abundantly expressed miRNA in mammalian cells, whose upregulation is associated with numerous types of cancer $(3,4)$. By generation of a conditional miR-21 knock-in mouse, it was demonstrated that miR-21 functions as an oncogene with its overexpression resulting in malignant B-cell lymphoma (5). Indeed, miR-21 was found to be the only consistently upregulated miRNA in a study that profiled 540 clinical samples from cancer patients (6). The majority of studies on miR-21 have focused on its role in carcinogenesis and its clinical application. miR-21 is also expressed in hematopoietic cells of the immune system, including $\mathrm{B} / \mathrm{T}$ cells, monocytes, macrophages and dendritic cells. High miR-21 levels are, therefore, considered to be a marker of immune cell activation (7). Regarding pathological necrosis, miR-21 enhances cellular necrosis by negatively regulating tumor suppressor genes associated with the death receptor-mediated intrinsic apoptotic pathway (8).

\section{Biological function of miR-21}

The biological functions of various miRNAs, including miR-21, have been extensively investigated and miR-21 is 


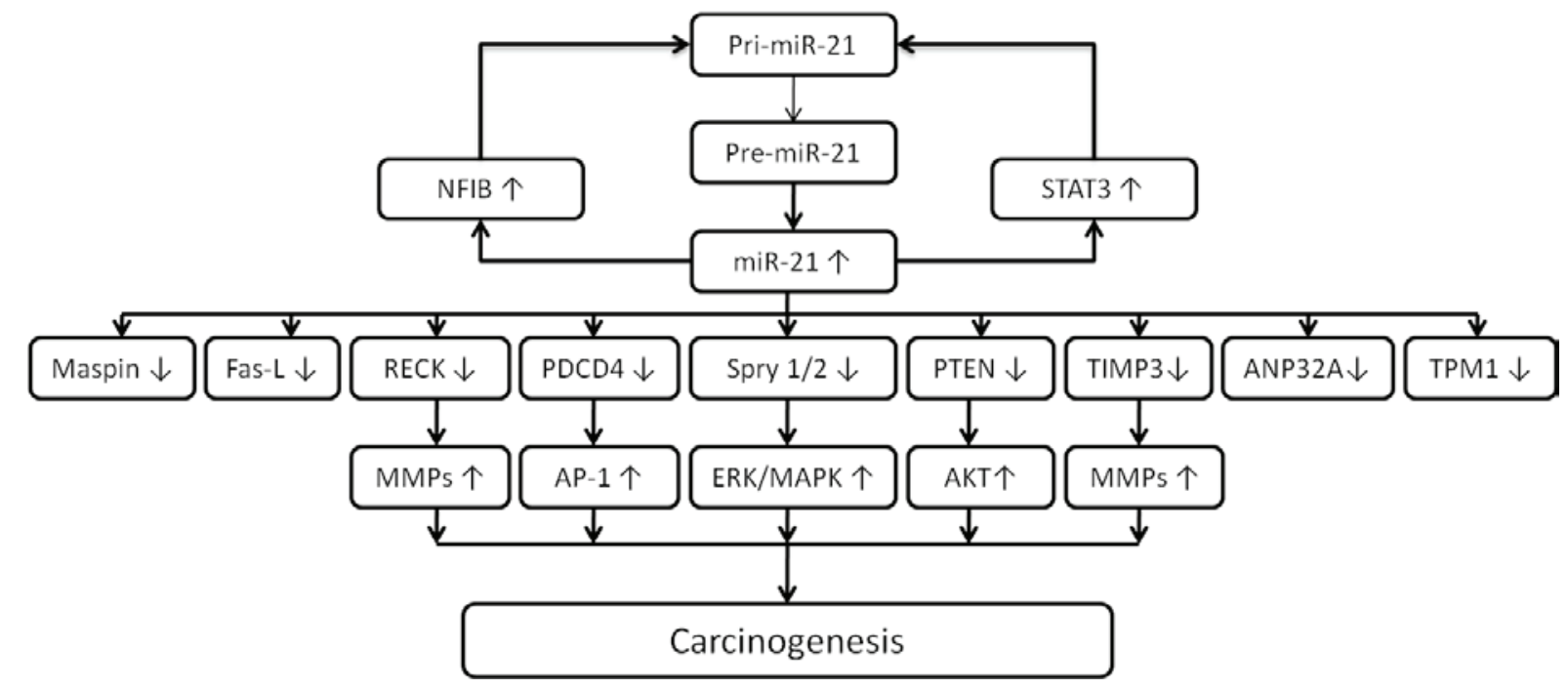

Figure 1. Pathways of the involvement of miR-21 in carcinogenesis. miR, microRNA; pri-mRNA, primary mRNA; pre-mRNA, precursor mRNA; AP-1, activated protein-1; NFI, nuclear factor I; Maspin, mammary serine protease inhibitor; Fas-L, Fas ligand; Spry 1/2, sprouty homolog 1/2; PDCD4, programmed cell death protein 4; TPM1, tropomyosin 1; RECK, reversion-induced cystine-rich protein with Kazal motifs; TIMP3, tissue inhibitor of metalloproteinases 3 ; ANP32A, acidic nuclear phosphoprotein 32 family, member A; MMP, matrix metalloproteinase; PTEN, phosphatase and tensin homologue deleted on chromosome 10; STAT3, signal transducer and activator of transcription 3; JNK, c-Jun N-terminal kinase; MDR, multi-drug resistance; ERK, extracellular signal-regulated kinase; MAPK, mitogen-associated protein kinase.

evolutionarily conserved across a wide range of vertebrate species (9). However, the location of the gene encoding miR-21 in the genome is different between humans and other vertebrate species. In rats and mice, the miR-21 gene is located on chromosome 10 and 21, respectively, whereas in humans, it is located on chromosome 17q23.2. The primary transcript of the miR-21 gene is independently transcribed from a conserved promoter located within the intron of the overlapping protein-coding gene (10). Experimental data have shown that in numerous cell types, miR-21 functions as an anti-apoptotic and pro-survival factor $(11,12)$. High expression levels of miR-21 may be a characteristic of cancer cells and represent a common feature of pathological cell growth or cell stress. For instance, miR-21 was shown to be upregulated in a mouse model of cardiac hypertrophy and vascular neointimal lesion formation $(13,14)$. The induction of miR-21 is associated with cellular de-differentiation. A noteworthy example is the restricted thyroid cell line FRTL-5, which depends on the presence of thyroid-stimulating hormone (15). These findings led to the hypothesis that relatively low levels of miR-21 may be temporarily and spatially required for differentiation and development, whereas high levels may exert oncogenic effects. Regarding the immune system, miR-21 has been shown to regulate T-cell immunity (16). Pro-inflammatory T helper (Th)1 and anti-inflammatory Th2 cells exist in a balanced state by counter-regulating each other's differentiation and function. miR-21 is induced in activated dendritic cells and directly targets the mRNA that encodes the p35 sub-unit of Th1-promoting interleukin (IL)-12, and in miR-21-deficient mice, increased secretion of IL-12 by dendritic cells as well as enhanced Th1 development have been observed (17). In addition to dendritic cell-derived miR-21, T-cell intrinsic miR-21 has been shown to promote Th2 differentiation by inhibiting the expression of Sprouty homolog (Spry) 1 transcript, a mitogen-activated protein kinase (MAPK) pathway inhibitor (18). Furthermore, miR-21 has been found to be overexpressed in $\mathrm{CD} 4^{+} \mathrm{T}$ cells derived from patients with lupus, as well as from lupus-prone MRL/lpr mice, indicating a strong association with autoimmune disease.

\section{Regulation of miR-21}

In Homo sapiens, miR-21 is located on chromosome 17q23.2, where it overlaps with the protein-coding gene transmembrane (TMEM)49, a human homolog of rat vacuole membrane protein. However, Fujita et al (19) reported that miR-21 and TMEM49 are independently regulated. Analysis of the consensus sequences within the miR-21 protein region identified several conserved enhancer elements, including binding sites for activation protein 1 (AP-1), Ets family transcription factor PU.1, CCAAT/enhancer-binding protein- $\alpha$, nuclear factor I (NFI), serum response element, p53 and signal transducer and activator of transcription 3 (STAT3) (20). A chromatin immunoprecipitation assay showed that AP-1 activated miR-21 transcription through conserved AP-1 and PU.1 binding sites and downregulated the expression of NFIB, a potential target of miR-21. Furthermore, the NFIB protein usually binds to the miR-21 promoter and acts as a negative regulator; therefore, a double-negative feedback mechanism operates between miR-21 and NFIB, which sustains miR-21 expression (21). Epigenetic modification appears to be involved in the regulation of miR-21 expression in specific cell types. One study revealed that miR-21 was among several miRNAs strongly induced in the ovarian cell line OVCAR3 by treatment with the demethylating agent 5-aza-2'-deoxycytidine and suggested that hypomethylation may be the mechanism responsible for its overexpression in vivo (22). Programmed cell death protein 4 (PDCD4), a direct target of miR-21 in solid and hematological malignancies, acts as a negative regulator of AP-1 (23). The activation of miR-21 by AP-1 in response to RAS oncoprotein led to downregulation of the expression of its target gene PDCD4, which then contributed to the increase 
in AP-1 activity. Hatley et al (24) provided the first in vivo evidence that miR-21 targets antagonists of RAS, including Spry1 and 2, B-cell translocation gene 2 (BTG2) and PDCD4, resulting in activation of the RAS/MAPK kinase/extracellular signal-regulated kinase pathway. In two studies, two-dimensional proteomics, luciferase reporter assays and western blot analysis were used to identify that tropomyosin 1 and acidic nuclear phosphoprotein 32 family, member $\mathrm{A}$ are targeted by miR-21, suppressing their translation $(25,26)$. As with TPM1 and PDCD4, maspin was found to be directly targeted by miR-21, which reduced the invasiveness of breast cancer cells. Therefore, the levels of PDCD4 and maspin are inversely correlated with miR-21 in human breast cancer (27). In addition, miR-21 regulates multiple genes associated with cell apoptosis, migration and invasiveness, including reversion-induced cystine-rich protein with Kazal motifs (RECK) and tissue inhibitor of metalloproteinases 3 (TIMP3), which are suppressors of malignancy and inhibitors of matrix metalloproteinases. mRNAs carrying RECK and TIMP3 have been predicted to be conserved miR-21 targets with one and two putative binding sites, respectively (Fig. 1) (28).

\section{Carcinogenesis}

miR-21 has been shown to be the most commonly upregulated miRNA in solid and hematological malignancies (6). Extensive studies have implicated its role in tumor pathogenesis and during all other stages of carcinogenesis. To date, the following functional studies have been performed, which strongly suggest that miR-21 exerts oncogenic activity: i) Knockdown of miR-21 in cultured glioblastoma cells triggered the activation of caspases and led to an increase in apoptotic cell death, suggesting that miR-21 acts as an anti-apoptotic factor (11); ii) the human miR-21 gene is located in the fragile site FRA17B within the 17q23.2 chromosomal region, which is one of the human papilloma virus (HPV) integration loci. Integration of HPV into the host cell genome caused genetic and epigenetic alterations, suggesting that the location of the miR-21 gene at or near HPV integration sites may contribute to its elevation in cervical cancer (29); iii) knockdown of miR-21 in hepatoma cells increased the expression level of tumor suppressor phosphatase and tensin homologue deleted on chromosome 10 (PTEN), a direct target of miR-21, and decreased tumor cell proliferation, migration and invasion (30). Furthermore, in colorectal cancer, miR-21 expression was found to be inversely correlated with Spry2 and PTEN leading to cancer progression (3); and iv) miR-21 was shown to promote hepatic lipid accumulation and cancer progression by interacting with the HMG-box transcription factor 1-p53-sterol regulatory element-binding transcription factor 1 pathway. An antisense oligonucleotide specific for miR-21 impaired liver lipid accumulation in mice and growth of xenograft tumors (31).

\section{5. miR-21 and hematological malignancies}

miR-21 has been identified as an 'oncomiR' in pre-B-cell lymphoma, and inhibition of miR-21 induced biological and behavioral alterations in diffuse large B-cell lymphoma (DLBCL) $(5,32)$. DLBCLs are known to be associated with the AKT signaling pathway, which is activated during carcinogenesis $(33,34)$. Furthermore, AKT activation is associated with poor prognosis of DLBCL patients (35). miR-21 activates the phosphoinositide-3 kinase (PI3K)/AKT signaling pathway by directly suppressing forkhead box protein O1 expression and downregulating PTEN expression (36). Natural killer (NK)-cell leukemia is a cancer type derived from NK cells, whose onset and development are, to a great extent, governed by Epstein-Barr virus (EBV). In addition, miR-21 was found to negatively regulate the tumor suppressors, PTEN and PDCD4 in NK-cell leukemia. EBV infection may contribute to the upregulation of various miRNAs, including miR-21 and miR-155, and infection with EBV is associated with immortalization of lymphoid cells $(37,38)$. In a study on a Chinese cohort with DLBCL, miR-21 expression was found to be elevated in the serum and correlated with the sub-type of activated B-cell lymphoma, as well as with early-stage disease (39). Jones et al (40) reported that circulating miR-21 along with miR-494 and miR-1973 was elevated in patients with classic Hodgkin lymphoma and indicated the disease response to therapy. These results suggest the potential use of miR-21 as non-invasive diagnostic markers.

Patients with chronic myeloid leukemia in the blastic phase show a poor response to clinical treatment (41); furthermore, retinol-binding protein 2, a histone $\mathrm{H} 3$ lysine 4 demethylase, was found to be underexpressed during the blastic phase of chronic myeloid leukemia, leading to epigenetic downregulation of miR-21 (42). Together with miR-155, miR-21 was found to be markedly overexpressed in patients with chronic lymphocytic leukemia (CLL) (4). IL-4 induces B-cell differentiation and survival of CLL cells, and regulation of miR-21 by IL-4 contributes to evasion of apoptosis of CLL cells (43). A study using an miR-21-based scoring system showed that miR-21 expression levels were significantly higher in CLL patients with chromosome 17 deletion (compared with CLL patients without chromosome 17 deletion), which was associated with poor prognosis (44). Although the investigation of miR-21 in acute leukemia is relatively insufficient, miR-21 is frequently overexpressed in myeloid blasts of patients with nucleophosmin-mutant acute myeloid leukemia and associated with a marked downregulation of PDCD4 protein (45). Lineage-tracing experiments revealed that Dicerl deficiency led to apoptosis of T-cell acute lymphoblastic leukemia (T-ALL) cells. Microarray-based miRNA profiling revealed that miR-21 was deregulated in mouse and human T-ALL cells. Furthermore, miR-21 was shown to regulate T-ALL cell survival via repression of the tumor suppressor PDCD4 (46). In addition, the tumor suppressor Spry2 was revealed to be negatively correlated with miR-21 expression in myeloma cells. Inhibition of miR-21 led to upregulation of PTEN and downregulation of phosphorylated AKT in xenografts of myeloma $(47,48)$. These results suggested that miR-21 is important in hematological malignancies.

\section{6. miR-21 and solid tumors}

Extensive studies have implicated the integral role of miR-21 in tumor pathogenesis and during all other stages of carcinogenesis. Growing evidence supports miR-21 expression as an important biomarker of poor prognosis in human 
malignancies (49). Generally, the expression level of miR-21 has been found to be higher in more advanced malignancies. A previous study indicated that high-grade glioma tended to have higher expression levels of miR-21 than low-grade glioma (11). In breast cancer, overexpression of miR-21 was significantly correlated with advanced clinical stage, lymph node metastasis and poor prognosis (50). Increased expression of miR-21 has been found in human breast cancer cell lines in vitro as well as in tissue samples, with a key role in all phases of breast cancer pathogenesis (51). Overexpression of the receptor tyrosine kinase HER 2 accounts for a clinically aggressive breast cancer sub-type with an increased incidence of metastasis. STAT3 co-opts the function of nuclear HER2 by recruiting it as its co-activator at the response elements in the promoter of miR-21. miR-21, in turn, was found to downregulate the expression of the metastasis suppressor protein PDCD4 in breast cancer (52). Further studies disclosed that serum and urine miR-21 may be a potential diagnostic biomarker for breast cancer; however, prior to its implementation in the clinic, further investigation is warranted $(53,54)$.

The expression of miR-21 is also critical in colon cancer. During the carcinogenesis of colon cancer, miR-21 induces stemness by downregulating transforming growth factor $\beta$ receptor 2 and stimulating invasion, as well as metastasis by suppressing PDCD4 $(55,56)$. miR-21 has been extensively investigated for its prognostic potential in at least ten independent trials involving 2,039 patients since 2008 (57). Nielsen et al (58) evaluated the expression of miR-21 using semi-quantitative in situ hybridization analysis of formalin-fixed, paraffin-embedded tissue samples from 197 patients with stage II colorectal cancer. Strong staining for miR-21 was significantly associated with shorter disease-free survival and overall survival. Furthermore, a large multicenter retrospective trial assessed the association between miRNAs and stage II colon cancer in a Chinese population. Six selected indicator miRNAs, comprising four upregulated miRNAs (miR-21, miR-20, miR-103 and miR-106) and two downregulated miRNAs (miR-143 and miR-215) were assessed to predict disease recurrence. Forty-six percent of the high-risk patients experienced a relapse and $15 \%$ of the low-risk group exhibited recurrence (59).

In non-small cell lung cancer (NSCLC), miR-21 enhances oncogenic K-ras activation and modulates tumorigenesis by targeting Spry2, BTG2 and PDCD4 (24). The epidermal growth factor receptor (EGFR) pathway has been regarded as an important mechanism in lung adenocarcinoma. miR-21 expression was found to be significantly increased in cases of lung adenocarcinoma with EGFR mutations, and activated EGFR signaling enhanced miR-21 expression (60). A meta-analysis of eight eligible studies revealed that miR-21 expression is a significant negative prognostic factor in Asian populations (61). The association of miR-21 with reduced overall survival has been evidenced in head and neck carcinoma, as well as in carcinoma of the digestive system (62). In addition, serum miR-21 was found have prognostic value in hepatoma and to promote the development of hepatoma by regulating PDCD4 and PTEN (63). Extensive studies have investigated the role of miR-21 in prostate carcinogenesis driven by the androgen receptor (64). Downregulation of RECK and loss of BTG2 mediated by miR-21 was shown to contribute to prostate cell transformation $(65,66)$. Furthermore, $\mathrm{miR}$ in prostate cancer tissues and in serum and urine samples of prostate cancer patients was revealed to be an independent diagnostic and prognostic biomarker (67-69).

Furthermore, miR-21 has been associated with the resistance of cancer to drug treatments. Inhibition of miR-21 may effectively reverse drug resistance in various cancer types (70). miR-21 is also implicated in drug resistance of breast cancer. In estrogen-positive breast cancer, downregulation of PDCD4 was found to be mediated by upregulation of HER2 via the MAPK and AKT signaling pathways, as well as miR-21 in aromatase inhibitor-resistant breast cancer cells (71). An in vitro study on breast cancer reported that silencing of miR-21 conferred sensitivity to tamoxifen and fulvestrant by enhancing autophagic cell death through inhibition of the PI3K-AKT-mammalian target of rapamycin pathway (72). Induction of miR-21 by interaction of hyaluronan-CD44 with protein kinase $\mathrm{C}$ and c-Jun has also been reported to contribute to chemotherapy resistance (73). Regarding anti-HER2 therapy of breast cancer, upregulation of miR-21 conferred resistance to trastuzumab along with a reduction of PTEN expression (74). The Geparquinto trial showed a negative association of circulating miR-21 with overall survival in HER2-positive breast cancer patients treated with neoadjuvant chemotherapy and trastuzumab or lapatinib (75). In HT-29 colon cancer cells, miR-21 targeted the human nuts homolog 2 , leading to the expression of thymidine phosphorylase and dihydropyrimidine dehydrogenase. These mechanisms conferred resistance of colon cancer cells to fluorouracil (76). In addition to the well-known platinum-based chemotherapy for lung cancer, miR-21 has been shown to be involved in the resistance to the EGFR inhibitor. EGFR-tyrosine kinase inhibitor (TKI) has been regarded as an important treatment option for NSCLC and miR-21 overexpression was found to be associated with acquired resistance to EGFR-TKI (77,78). A pilot study using plasma miRNA profiles identified miR-21 to be involved in the primary resistance to EGFR-TKI in patients with advanced NSCLC with an activating EGFR mutation. The application of this non-invasive approach may be considered for monitoring responses of lung cancer patients to EGFR-TKI treatment (79). Furthermore, the implication of miR-21 in chemotherapy resistance has been investigated for a wide range of solid cancer types, including pancreatic and prostate cancer, hepatoma, ovarian cancer, glioma, and head and neck, stomach and bladder cancer (Table I) (68-71,75,77-94). These results support the clinical application of miR-21 inhibition in cancer treatments in the future.

\section{Conclusion}

Evidence supports that miR-21 is an oncogenic miRNA and regulates various downstream effectors associated with cancer. Overexpression of miR-21 is strongly associated with hematological and solid malignancies. miR-21 may be utilized as a diagnostic and prognostic biomarker for various types of cancer and as a potential therapeutic target. Based on this concept, further research on miRNA signaling pathways has begun with the aim of elucidating their effects on conventional protein signaling pathways. The implication of miR-21 in resistance to anticancer agents highlights the possible clinical 
Table I. Studies on the involvement of miR-21 in the resistance of solid malignancies to anticancer agents.

\begin{tabular}{|c|c|c|c|c|}
\hline Cancer type & Anticancer agent & Signaling pathway & Model & Author, year (Refs.) \\
\hline Breast & Aromatase inhibitor & HER2/PDCD4 & Cell, human & Chen et al, 2015 (71) \\
\hline Breast & Tamoxifen/fulvestrant & PI3K-mTOR & Cell & Yu et al, 2016 (72) \\
\hline Breast & Doxorubicin/paclitaxel & HA-CD44 & Cell & Bourguignon et al, 2009 (73) \\
\hline Breast & Trastuzumab & PTEN & Cell, mice, human & Gong et al, 2011 (74) \\
\hline Lung & Gefitninb & PTEN & Cell, mice & Shen et al, 2014 (78) \\
\hline Breast & Gemcitabine & PTEN/AKT & Cell, mice & Wu et al, 2016 (80) \\
\hline Colon & 5FU/oxaliplatin & TGF $\beta$ & Cell & Yu et al, 2012 (81) \\
\hline Colon & $5 \mathrm{FU}$ & Sprouty 2 & Cell & Feng et al, 2012 (82) \\
\hline Lung & Cisplatin & PTEN & Cell, human & Liu et al, 2013 (83) \\
\hline Pancreas & $5 \mathrm{FU}$ & PTEN/PDCD4 & Cell & Wei et al, 2016 (84) \\
\hline Pancreas & Gemcitabine & PDCD4 & Cell & Paik et al, 2013 (85) \\
\hline Prostate & Docetaxel & PDCD4 & Cell & Shi et al, 2010 (86) \\
\hline Liver & Interferon- $\alpha / 5 \mathrm{FU}$ & PTEN/PDCD4 & Cell, human & Tomimaru et al, 2010 (87) \\
\hline Liver & Sorafenib & PTEN/AKT & Cell, mice & He et al, $2015(88)$ \\
\hline Ovary & Cisplatin & JNK/c-JUN & Cell & Echevarria-Vargas et al, 2014 (89) \\
\hline Ovary & Paclitaxel & MDR-1/P-gp & Cell & Xie et al, 2013 (90) \\
\hline Brain (glioma) & Temozolomide & Wnt $/ \beta$-catenin & Cell & Lan et al, 2015 (91) \\
\hline Brain (glioma) & Temozolomide & $\mathrm{Bax} / \mathrm{Bcl}-2$ & Cell & Shi et al, 2010 (92) \\
\hline $\begin{array}{l}\text { Head and neck } \\
\text { (oral cancer) }\end{array}$ & Cisplatin & PTEN/TIMP3/PDCD4 & Cell, mice & Zhou et al, 2014 (93) \\
\hline Head and neck & Cisplatin & HA-CD44/PDCD4/IAP & Cell & Bourguignon et al, 2012 (94) \\
\hline $\begin{array}{l}\text { Head and neck } \\
\text { (nasopharyngeal } \\
\text { cancer) }\end{array}$ & Cisplatin & PDCD4/Fas-L & Cell & Yang et al, 2013 (95) \\
\hline Stomach & Cisplatin & PTEN & Cell & Yang et al, 2013 (96) \\
\hline Bladder & Doxorubicin & PTEN & Cell & Tao et al, 2011 (97) \\
\hline
\end{tabular}

FU, fluorouracil; mTOR, mammalian target of rapamycin; PI3K, phosphoinositide-3 kinase; JNK, c-Jun N-terminal kinase; PTEN, phosphatase and tensin homologue deleted on chromosome 10; PDCD4, programmed cell death protein 4; MDR, multi-drug resistance; P-gp, p-glycoprotein; Bcl-2, B-cell lymphoma 2; Bax, Bcl-2-associated X protein; TIMP3, tissue inhibitor of metalloproteinases 3; HA, hyaluronan; IAP, inhibitor of apoptosis; Fas-L, Fas ligand.

application of miR-21 inhibition for reducing the resistance of cancer to drugs, with the potential to use targeted therapeutic strategies in addition to conventional cytotoxic agents. In 2013 , a clinical trial using an miRNA was launched (NCT01829971; ClinicalTrial.gov). The study evaluates the safety of an miRNARX34 liposomal injection in patients with primary liver cancer as well as other selected solid tumor types and hematological malignancies. To the best of our knowledge there are no ongoing miR-21-based clinical trials on cancer patients. Further studies are required prior to implementing miRNA-based cancer therapeutic strategies into clinical practice. Furthermore, development of effective delivery methods of synthetic therapeutic miRNAs to desired target tissues may enhance the efficacy of miRNA-mediated treatments, enabling the adoption of this type of therapy in cancer medicine in future.

\section{Acknowledgements}

The present study was supported by a grant from the Chi-Mei Medical Center (Tainan, Taiwan ROC; grant no. CMNCKU 10113 to Y.F.).

\section{References}

1. Griffiths-Jones S, Grocock RJ, van Dongen S, Bateman A and Enright AJ: miRBase: microRNA sequences, targets and gene nomenclature. Nucleic Acids Res 34: D140-D144, 2006.

2. Kim VN: MicroRNA biogenesis: Coordinated cropping and dicing. Nat Rev Mol Cell Biol 6: 376-385, 2005.

3. Feng YH, Wu CL, Tsao CJ, Chang JG, Lu PJ, Yeh KT, Uen YH, Lee JC and Shiau AL: Deregulated expression of sprouty2 and microRNA-21 in human colon cancer: Correlation with the clinical stage of the disease. Cancer Biol Ther 11: 111-121, 2011.

4. Fulci V, Chiaretti S, Goldoni M, Azzalin G, Carucci N, Tavolaro S, Castellano L, Magrelli A, Citarella F, Messina M, et al: Quantitative technologies establish a novel microRNA profile of chronic lymphocytic leukemia. Blood 109: 4944-4951, 2007.

5. Medina PP, Nolde M and Slack FJ: OncomiR addiction in an in vivo model of microRNA-21-induced pre-B-cell lymphoma. Nature 467: 86-90, 2010.

6. Volinia S, Calin GA, Liu CG, Ambs S, Cimmino A, Petrocca F, Visone R, Iorio M, Roldo C, Ferracin M, et al: A microRNA expression signature of human solid tumors defines cancer gene targets. Proc Natl Acad Sci USA 103: 2257-2261, 2006.

7. Sheedy FJ: Turning 21: Induction of miR-21 as a key switch in the inflammatory response. Front Immunol 6: 19, 2015.

8. Ma X, Conklin DJ, Li F, Dai Z, Hua X, Li Y, Xu-Monette ZY, Young KH, Xiong W, Wysoczynski M, et al: The oncogenic microRNA miR-21 promotes regulated necrosis in mice. Nat Commun 6: 7151,2015. 
9. Krichevsky AM and Gabriely G: miR-21: A small multi-faceted RNA. J Cell Mol Med 13: 39-53, 2009.

10. Selcuklu SD, Donoghue MT and Spillane C: miR-21 as a key regulator of oncogenic processes. Biochem Soc Trans 37: 918-925, 2009.

11. Chan JA, Krichevsky AM and Kosik KS: MicroRNA-21 is an antiapoptotic factor in human glioblastoma cells. Cancer Res 65: 6029-6033, 2005.

12. Roldo C, Missiaglia E, Hagan JP, Falconi M, Capelli P, Bersani S, Calin GA, Volinia S, Liu CG, Scarpa A, et al: MicroRNA expression abnormalities in pancreatic endocrine and acinar tumors are associated with distinctive pathologic features and clinical behavior. J Clin Oncol 24: 4677-4684, 2006.

13. Tatsuguchi M, Seok HY, Callis TE, Thomson JM, Chen JF, Newman M, Rojas M, Hammond SM and Wang DZ: Expression of microRNAs is dynamically regulated during cardiomyocyte hypertrophy. J Mol Cell Cardiol 42: 1137-1141, 2007.

14. Ji R, Cheng Y, Yue J, Yang J, Liu X, Chen H, Dean DB and Zhang C: MicroRNA expression signature and antisense-mediated depletion reveal an essential role of MicroRNA in vascular neointimal lesion formation. Circ Res 100: 1579-1588, 2007.

15. Landgraf P, Rusu M, Sheridan R, Sewer A, Iovino N, Aravin A, Pfeffer S, Rice A, Kamphorst AO, Landthaler M, et al: A mammalian microRNA expression atlas based on small RNA library sequencing. Cell 129: 1401-1414, 2007.

16. Lu TX, Munitz A and Rothenberg ME: MicroRNA-21 is up-regulated in allergic airway inflammation and regulates IL-12p35 expression. J Immunol 182: 4994-5002, 2009.

17. Lu TX, Hartner J, Lim EJ, Fabry V, Mingler MK, Cole ET, Orkin SH, Aronow BJ and Rothenberg ME: MicroRNA-21 limits in vivo immune response-mediated activation of the IL-12/IFN-gamma pathway, Th1 polarization, and the severity of delayed-type hypersensitivity. J Immunol 187: 3362-3373, 2011.

18. Murugaiyan G, Garo LP and Weiner HL: MicroRNA-21, T helper lineage and autoimmunity. Oncotarget 6: 9644-9645, 2015.

19. Fujita S, Ito T, Mizutani T, Minoguchi S, Yamamichi N, Sakurai K and Iba H: miR-21 Gene expression triggered by AP-1 is sustained through a double-negative feedback mechanism. J Mol Biol 378: 492-504, 2008.

20. Pan X, Wang ZX and Wang R: MicroRNA-21: A novel therapeutic target in human cancer. Cancer Biol Ther 10: 1224-1232, 2010.

21. Löffler D, Brocke-Heidrich K, Pfeifer G, Stocsits C, Hackermüller J, Kretzschmar AK, Burger R, Gramatzki M, Blumert C, Bauer K, et al: Interleukin-6 dependent survival of multiple myeloma cells involves the Stat3-mediated induction of microRNA-21 through a highly conserved enhancer. Blood 110: $1330-1333,2007$

22. Iorio MV, Visone R, Di Leva G, Donati V, Petrocca F, Casalini P, Taccioli C, Volinia S, Liu CG, Alder H, et al: MicroRNA signatures in human ovarian cancer. Cancer Res 67: 8699-8707, 2007.

23. Yang HS, Knies JL, Stark C and Colburn NH: Pdcd4 suppresses tumor phenotype in JB6 cells by inhibiting AP-1 transactivation. Oncogene 22: 3712-3720, 2003.

24. Hatley ME, Patrick DM, Garcia MR, Richardson JA Bassel-Duby R, van Rooij E and Olson EN: Modulation of K-Ras-dependent lung tumorigenesis by MicroRNA-21. Cancer Cell 18: 282-293, 2010.

25. Zhu S, Si ML, Wu H and Mo YY: MicroRNA-21 targets the tumor suppressor gene tropomyosin 1 (TPM1). J Biol Chem 282 14328-14336, 2007.

26. Schramedei K, Mörbt N, Pfeifer G, Läuter J, Rosolowski M, Tomm JM, von Bergen M, Horn F and Brocke-Heidrich K: MicroRNA-21 targets tumor suppressor genes ANP32A and SMARCA4. Oncogene 30: 2975-2985, 2011.

27. Zhu S, Wu H, Wu F, Nie D, Sheng S and Mo YY: MicroRNA-21 targets tumor suppressor genes in invasion and metastasis. Cell Res 18: 350-359, 2008.

28. Gabriely G, Wurdinger T, Kesari S, Esau CC, Burchard J, Linsley PS and Krichevsky AM: MicroRNA 21 promotes glioma invasion by targeting matrix metalloproteinase regulators. Mol Cell Biol 28: 5369-5380, 2008.

29. Thorland EC, Myers SL, Gostout BS and Smith DI: Common fragile sites are preferential targets for HPV16 integrations in cervical tumors. Oncogene 22: 1225-1237, 2003.

30. Meng F, Henson R, Wehbe-Janek H, Ghoshal K, Jacob ST and Patel T: MicroRNA-21 regulates expression of the PTEN tumor suppressor gene in human hepatocellular cancer. Gastroenterology 133: 647-658, 2007.

31. Wu H, Ng R, Chen X, Steer CJ and Song G: MicroRNA-21 is a potential link between non-alcoholic fatty liver disease and hepatocellular carcinoma via modulation of the HBP1-p53-Srebp1c pathway. Gut gutjnl-2014-308430, 2015.
32. Gu L, Song G, Chen L, Nie Z, He B, Pan Y, Xu Y, Li R, Gao T, Cho WC, et al: Inhibition of miR-21 induces biological and behavioral alterations in diffuse large B-cell lymphoma. Acta Haematol 130: 87-94, 2013

33. Davis RE, Ngo VN, Lenz G, Tolar P, Young RM, Romesser PB, Kohlhammer H, Lamy L, Zhao H, Yang Y, et al: Chronic active B-cell-receptor signalling in diffuse large B-cell lymphoma. Nature 463: 88-92, 2010.

34. Pfeifer M, Grau M, Lenze D, Wenzel SS, Wolf A, Wollert-Wulf B, Dietze K, Nogai H, Storek B, Madle H, et al: PTEN loss defines a PI3K/AKT pathway-dependent germinal center subtype of diffuse large B-cell lymphoma. Proc Natl Acad Sci USA 110: 12420-12425, 2013.

35. Hong JY, Hong ME, Choi MK, Kim YS, Chang W, Maeng CH, Park S, Lee SJ, Do IG, Jo JS, et al: The impact of activated p-AKT expression on clinical outcomes in diffuse large B-cell lymphoma: A clinicopathological study of 262 cases. Ann Oncol 25: 182-188, 2014.

36. Go H, Jang JY, Kim PJ, Kim YG, Nam SJ, Paik JH, Kim TM, Heo DS, Kim CW and Jeon YK: MicroRNA-21 plays an oncogenic role by targeting FOXO1 and activating the PI3K/AKT pathway in diffuse large B-cell lymphoma. Oncotarget 6: 15035-15049, 2015.

37. Karube K, Nakagawa M, Tsuzuki S, Takeuchi I, Honma K, Nakashima Y, Shimizu N, Ko YH, Morishima Y,Ohshima K, et al: Identification of FOXO3 and PRDM1 as tumor-suppressor gene candidates in NK-cell neoplasms by genomic and functional analyses. Blood 118: 3195-3204, 2011.

38. Yin Q, McBride J, Fewell C, Lacey M, Wang X, Lin Z, Cameron J and Flemington EK: MicroRNA-155 is an Epstein-Barr virus-induced gene that modulates Epstein-Barr virus-regulated gene expression pathways. J Virol 82: 5295-5306, 2008.

39. Chen W, Wang H, Chen H, Liu S, Lu H, Kong D, Huang X, Kong Q and Lu Z: Clinical significance and detection of microRNA-21 in serum of patients with diffuse large B-cell lymphoma in Chinese population. Eur J Haematol 92: 407-412, 2014.

40. Jones K, Nourse JP, Keane C, Bhatnagar A and Gandhi MK Plasma microRNA are disease response biomarkers in classical Hodgkin lymphoma. Clin Cancer Res 20: 253-264, 2014.

41. Anger B, Carbonell F, Braunger I, Heinze B, Gutensohn W, Thiel E and Heimpel H: Blast crisis of Philadelphia chromosome-positive chronic myelocytic leukemia (CML). Treatment results of 69 patients. Blut 57: 131-137, 1988.

42. Zhou M, Zeng J, Wang X, Wang X, Huang T, Fu Y, Sun T, Jia J and Chen C: Histone demethylase RBP2 decreases miR-21 in blast crisis of chronic myeloid leukemia. Oncotarget 6 : $1249-1261,2015$

43. Ruiz-Lafuente N, Alcaraz-García MJ, Sebastián-Ruiz S, García-Serna AM, Gómez-Espuch J, Moraleda JM, Minguela A, García-Alonso AM and Parrado A: IL-4 up-regulates MiR-21 and the MiRNAs hosted in the CLCN5 gene in chronic lymphocytic leukemia. PLoS One 10: e0124936, 2015.

44. Rossi S, Shimizu M, Barbarotto E, Nicoloso MS, Dimitri F, Sampath D, Fabbri M, Lerner S, Barron LL, Rassenti LZ, et al: microRNA fingerprinting of CLL patients with chromosome 17p deletion identify a miR-21 score that stratifies early survival. Blood 116: 945-952, 2010.

45. Riccioni R, Lulli V, Castelli G, Biffoni M, Tiberio R, Pelosi E, Lo-Coco F and Testa U: miR-21 is overexpressed in NPM1-mutant acute myeloid leukemias. Leuk Res 39: 221-228, 2015.

46. Junker F, Chabloz A, Koch U and Radtke F: Dicer1 imparts essential survival cues in Notch-driven T-ALL via miR-21-mediated tumor suppressor Pdcd4 repression. Blood 126 993-1004, 2015.

47. Leone E, Morelli E, Di Martino MT, Amodio N, Foresta U, Gullà A, Rossi M, Neri A, Giordano A, Munshi NC, et al: Targeting miR-21 inhibits in vitro and in vivo multiple myeloma cell growth. Clin Cancer Res 19: 2096-2106, 2013.

48. Wang JH, Zhou WW, Cheng ST, Liu BX, Liu FR and Song JQ: Downregulation of Sprouty homolog 2 by microRNA-21 inhibits proliferation, metastasis and invasion, however promotes the apoptosis of multiple myeloma cells. Mol Med Rep 12: 1810-1816, 2015.

49. Wang W, Li J, Zhu W, Gao C, Jiang R, Li W, Hu Q and Zhang B: MicroRNA-21 and the clinical outcomes of various carcinomas: A systematic review and meta-analysis. BMC Cancer 14: 819, 2014

50. Yan LX, Huang XF, Shao Q, Huang MY, Deng L, Wu QL, Zeng YX and Shao JY: MicroRNA miR-21 overexpression in human breast cancer is associated with advanced clinical stage, lymph node metastasis and patient poor prognosis. RNA 14: 2348-2360, 2008. 
51. Zhang ZJ and Ma SL: miRNAs in breast cancer tumorigenesis (Review). Oncol Rep 27: 903-910, 2012.

52. Venturutti L, Romero LV, Urtreger AJ, Chervo MF, Cordo Russo RI, Mercogliano MF, Inurrigarro G, Pereyra MG, Proietti CJ, Izzo F, et al: Stat3 regulates ErbB-2 expression and co-opts ErbB-2 nuclear function to induce miR-21 expression, PDCD 4 downregulation and breast cancer metastasis. Oncogene 35: 2208-2222, 2015.

53. Erbes T, Hirschfeld M, Rücker G, Jaeger M, Boas J, Iborra S, Mayer S, Gitsch G and Stickeler E: Feasibility of urinary microRNA detection in breast cancer patients and its potential as an innovative non-invasive biomarker. BMC Cancer 15: $193,2015$.

54. Li S, Yang X, Yang J, Zhen J and Zhang D: Serum microRNA-21 as a potential diagnostic biomarker for breast cancer: A systematic review and meta-analysis. Clin Exp Med 16: 29-35, 2014.

55. Asangani IA, Rasheed SA, Nikolova DA, Leupold JH, Colburn NH, Post S and Allgayer H: MicroRNA-21 (miR-21) post-transcriptionally downregulates tumor suppressor Pdcd4 and stimulates invasion, intravasation and metastasis in colorectal cancer. Oncogene 27: 2128-2136, 2008.

56. Yu Y, Nangia-Makker P, Farhana L, G Rajendra S, Levi E and Majumdar AP: miR-21 and miR-145 cooperation in regulation of colon cancer stem cells. Mol Cancer 14: 98, 2015.

57. Dong Y, Yu J and Ng SS: MicroRNA dysregulation as a prognostic biomarker in colorectal cancer. Cancer Manag Res 6: 405-422, 2014

58. Nielsen BS, Jørgensen S, Fog JU, Søkilde R, Christensen IJ, Hansen U, Brünner N, Baker A, Møller S and Nielsen HJ: High levels of microRNA-21 in the stroma of colorectal cancers predict short disease-free survival in stage II colon cancer patients. Clin Exp Metastasis 28: 27-38, 2011.

59. Zhang JX, Song W, Chen ZH, Wei JH, Liao YJ, Lei J, Hu M, Chen GZ, Liao B, Lu J, et al: Prognostic and predictive value of a microRNA signature in stage II colon cancer: A microRNA expression analysis. Lancet Oncol 14: 1295-1306, 2013.

60. Seike M, Goto A, Okano T, Bowman ED, Schetter AJ, Horikawa I, Mathe EA, Jen J, Yang P, Sugimura H, et al: miR-21 is an EGFR-regulated anti-apoptotic factor in lung cancer in never-smokers. Proc Natl Acad Sci USA 106: 12085-12090, 2009

61. Ma XL, Liu L, Liu XX, Li Y, Deng L, Xiao ZL, Liu YT, Shi HS and Wei YQ: Prognostic role of microRNA-21 in non-small cell lung cancer: A meta-analysis. Asian Pac J Cancer Prev 13: 2329-2334, 2012

62. Fu X, Han Y, Wu Y, Zhu X, Lu X, Mao F, Wang X, He X, Zhao $Y$ and Zhao Y: Prognostic role of microRNA-21 in various carcinomas: A systematic review and meta-analysis. Eur J Clin Invest 41: 1245-1253, 2011.

63. Wang X, Zhang J, Zhou L, Lu P, Zheng ZG, Sun W, Wang JL, Yang XS, Li XL, Xia N, et al: Significance of serum microRNA-21 in diagnosis of hepatocellular carcinoma (HCC): Clinical analyses of patients and an HCC rat model. Int J Clin Exp Pathol 8: 1466-1478, 2015.

64. Ribas J, Ni X, Haffner M, Wentzel EA, Salmasi AH, Chowdhury WH, Kudrolli TA, Yegnasubramanian S, Luo J, Rodriguez R, et al: miR-21: An androgen receptor-regulated microRNA that promotes hormone-dependent and hormone-independent prostate cancer growth. Cancer Res 69: 7165-7169, 2009.

65. Reis ST, Pontes-Junior J, Antunes AA, Dall'Oglio MF, Dip N, Passerotti CC, Rossini GA, Morais DR, Nesrallah AJ, Piantino C, et al: miR-21 may acts as an oncomir by targeting RECK, a matrix metalloproteinase regulator, in prostate cancer. BMC Urol 12: 14, 2012

66. Coppola V, Musumeci M, Patrizii M, Cannistraci A, Addario A, Maugeri-Saccà M, Biffoni M, Francescangeli F, Cordenonsi M, Piccolo S, et al: BTG2 loss and miR-21 upregulation contribute to prostate cell transformation by inducing luminal markers expression and epithelial-mesenchymal transition. Oncogene 32: $1843-1853,2013$

67. Li T, Li RS, Li YH, Zhong S, Chen YY, Zhang CM, Hu MM and Shen ZJ: miR-21 as an independent biochemical recurrence predictor and potential therapeutic target for prostate cancer. J Urol 187: 1466-1472, 2012.

68. Samsonov R, Shtam T, Burdakov V, Glotov A, Tsyrlina E, Berstein L, Nosov A, Evtushenko V, Filatov M and Malek A: Lectin-induced agglutination method of urinary exosomes isolation followed by mi-RNA analysis: Application for prostate cancer diagnostic. Prostate 76: 68-79, 2016
69. Koppers-Lalic D, Hackenberg M, de Menezes R, Misovic B, Wachalska M, Geldof A, Zini N, de Reijke T, Wurdinger T, Vis A, et al: Non-invasive prostate cancer detection by measuring miRNA variants (isomiRs) in urine extracellular vesicles. Oncotarget 7: 22566-22578, 2016.

70. Hong L, Han Y, Zhang Y, Zhang H, Zhao Q, Wu K and Fan D: MicroRNA-21: A therapeutic target for reversing drug resistance in cancer. Expert Opin Ther Targets 17: 1073-1080, 2013.

71. Chen Z, Yuan YC, Wang Y, Liu Z, Chan HJ and Chen S: Down-regulation of programmed cell death 4 (PDCD4) is associated with aromatase inhibitor resistance and a poor prognosis in estrogen receptor-positive breast cancer. Breast Cancer Res Treat 152: 29-39, 2015

72. Yu X, Li R, Shi W, Jiang T, Wang Y, Li C and Qu X: Silencing of MicroRNA-21 confers the sensitivity to tamoxifen and fulvestrant by enhancing autophagic cell death through inhibition of the PI3K-AKT-mTOR pathway in breast cancer cells. Biomed Pharmacother 77: 37-44, 2016

73. Bourguignon LY, Spevak CC, Wong G, Xia W and Gilad E: Hyaluronan-CD44 interaction with protein kinase C(epsilon) promotes oncogenic signaling by the stem cell marker Nanog and the Production of microRNA-21, leading to down-regulation of the tumor suppressor protein PDCD4, anti-apoptosis, and chemotherapy resistance in breast tumor cells. J Biol Chem 284: 26533-26546, 2009.

74. Gong C, Yao Y, Wang Y, Liu B, Wu W, Chen J, Su F, Yao H and Song E: Up-regulation of miR-21 mediates resistance to trastuzumab therapy for breast cancer. J Biol Chem 286: 19127-19137, 2011

75. Müller V, Gade S, Steinbach B, Loibl S, von Minckwitz G, Untch M, Schwedler K, Lübbe K, Schem C, Fasching PA, et al: Changes in serum levels of miR-21, miR-210, and miR-373 in HER2-positive breast cancer patients undergoing neoadjuvant therapy: A translational research project within the Geparquinto trial. Breast Cancer Res Treat 147: 61-68, 2014.

76. Deng J, Lei W, Fu JC, Zhang L, Li JH and Xiong JP: Targeting miR-21 enhances the sensitivity of human colon cancer HT-29 cells to chemoradiotherapy in vitro. Biochem Biophys Res Commun 443: 789-795, 2014

77. Li B, Ren S, Li X, Wang Y, Garfield D, Zhou S, Chen X, Su C, Chen M, Kuang P, et al: miR-21 overexpression is associated with acquired resistance of EGFR-TKI in non-small cell lung cancer. Lung Cancer 83: 146-153, 2014.

78. Shen H, Zhu F, Liu J, Xu T, Pei D, Wang R, Qian Y, Li Q, Wang L, Shi Z, et al: Alteration in Mir-21/PTEN expression modulates gefitinib resistance in non-small cell lung cancer. PLoS One 9: e103305, 2014

79. Wang S, Su X, Bai H, Zhao J, Duan J, An T, Zhuo M, Wang Z, $\mathrm{Wu} \mathrm{M}, \mathrm{Li} \mathrm{Z}$, et al: Identification of plasma microRNA profiles for primary resistance to EGFR-TKIs in advanced non-small cell lung cancer (NSCLC) patients with EGFR activating mutation. J Hematol Oncol 8: 127, 2015.

80. Wu ZH, Tao ZH, Zhang J, Li T, Ni C, Xie J, Zhang JF and Hu XC: miRNA-21 induces epithelial to mesenchymal transition and gemcitabine resistance via the PTEN/AKT pathway in breast cancer. Tumour Biol 37: 7245-7254, 2016.

81. Yu Y, Kanwar SS, Patel BB, Oh PS, Nautiyal J, Sarkar FH and Majumdar AP: MicroRNA-21 induces stemness by downregulating transforming growth factor beta receptor 2 (TGF $\beta R 2$ ) in colon cancer cells. Carcinogenesis 33: 68-76, 2012.

82. Feng YH, Wu CL, Shiau AL, Lee JC, Chang JG, Lu PJ, Tung CL, Feng LY, Huang WT and Tsao CJ: MicroRNA-21-mediated regulation of Sprouty 2 protein expression enhances the cytotoxic effect of 5-fluorouracil and metformin in colon cancer cells. Int J Mol Med 29: 920-926, 2012

83. Liu ZL, Wang H, Liu J and Wang ZX: MicroRNA-21 (miR-21) expression promotes growth, metastasis, and chemo- or radioresistance in non-small cell lung cancer cells by targeting PTEN. Mol Cell Biochem 372: 35-45, 2013.

84. Wei X, Wang W, Wang L, Zhang Y, Zhang X, Chen M, Wang F, Yu J, Ma Y and Sun G: MicroRNA-21 induces 5-fluorouracil resistance in human pancreatic cancer cells by regulating PTEN and PDCD4. Cancer Med 5: 693-702, 2016.

85. Paik WH, Kim HR, Park JK, Song BJ, Lee SH and Hwang JH: Chemosensitivity induced by down-regulation of microRNA-21 in gemcitabine-resistant pancreatic cancer cells by indole-3-carbinol. Anticancer Res 33: 1473-1481, 2013.

86. Shi GH, Ye DW, Yao XD, Zhang SL, Dai B, Zhang HL, Shen YJ, Zhu Y, Zhu YP, Xiao WJ, et al: Involvement of microRNA-21 in mediating chemo-resistance to docetaxel in androgen-independent prostate cancer PC3 cells. Acta Pharmacol Sin 31: 867-873, 2010. 
87. Tomimaru Y, Eguchi H, Nagano H, Wada H, Tomokuni A, Kobayashi S, Marubashi S, Takeda Y, Tanemura M, Umeshita K, et al: MicroRNA-21 induces resistance to the anti-tumour effect of interferon- $\alpha / 5$-fluorouracil in hepatocellular carcinoma cells. Br J Cancer 103: 1617-1626, 2010.

88. He C, Dong X, Zhai B, Jiang X, Dong D, Li B, Jiang H, Xu S and Sun X: miR-21 mediates sorafenib resistance of hepatocellular carcinoma cells by inhibiting autophagy via the PTEN/Akt pathway. Oncotarget 6: 28867-28881, 2015.

89. Echevarría-Vargas IM, Valiyeva F and Vivas-Mejía PE: Upregulation of miR-21 in cisplatin resistant ovarian cancer via JNK-1/c-Jun pathway. PLoS One 9: e97094, 2014.

90. Xie Z, Cao L and Zhang J: miR-21 modulates paclitaxel sensitivity and hypoxia-inducible factor- $1 \alpha$ expression in human ovarian cancer cells. Oncol Lett 6: 795-800, 2013.

91. Lan F, Pan Q, Yu H and Yue X: Sulforaphane enhances temozolomide-induced apoptosis because of down-regulation of miR-21 via Wnt/ $\beta$-catenin signaling in glioblastoma. J Neurochem 134: 811-818, 2015.

92. Shi L, Chen J, Yang J, Pan T, Zhang S and Wang Z: miR-21 protected human glioblastoma U87MG cells from chemotherapeutic drug temozolomide induced apoptosis by decreasing Bax/Bcl-2 ratio and caspase-3 activity. Brain Res 1352 255-264, 2010.
93. Zhou X, Ren Y, Liu A, Jin R, Jiang Q, Huang Y, Kong L, Wang X and Zhang L: WP1066 sensitizes oral squamous cell carcinoma cells to cisplatin by targeting STAT3/miR-21 axis. Sci Rep 4: 7461,2014

94. Bourguignon LY, Earle C, Wong G, Spevak CC and Krueger K: Stem cell marker (Nanog) and Stat-3 signaling promote MicroRNA-21 expression and chemoresistance in hyaluronan/CD44-activated head and neck squamous cell carcinoma cells. Oncogene 31: 149-160, 2012.

95. Yang GD, Huang TJ, Peng LX, Yang CF, Liu RY, Huang HB, Chu QQ, Yang HJ, Huang JL, Zhu ZY, et al: Epstein-Barr Virus_Encoded LMP1 upregulates microRNA-21 to promote the resistance of nasopharyngeal carcinoma cells to cisplatin-induced Apoptosis by suppressing PDCD4 and Fas-L. PLoS One 8: e78355, 2013

96. Yang SM, Huang C, Li XF, Yu MZ, He Y and Li J: miR-21 confers cisplatin resistance in gastric cancer cells by regulating PTEN. Toxicology 306: 162-168, 2013.

97. Tao J, Lu Q, Wu D, Li P, Xu B, Qing W, Wang M, Zhang Z and Zhang W: microRNA-21 modulates cell proliferation and sensitivity to doxorubicin in bladder cancer cells. Oncol Rep 25: 1721-1729, 2011. 